\title{
TGF- $\beta 1$ : is it related to the stiffness of breast lesions and can it predict axillary lymph node metastasis?
}

\author{
Meng Ke Zhang ${ }^{1 \#}$, Qiu Jing Shang ${ }^{2 \#}$, Shi Yu Li ${ }^{1}$, Bo Wang ${ }^{1}$, Gang Liu ${ }^{3}$, Zhi Li Wang ${ }^{1}$ \\ ${ }^{1}$ Department of Ultrasound, First Medical Center of Chinese People's Liberation Army General Hospital, Beijing, China; ${ }^{2}$ Department of \\ Ultrasound, Fifth Medical Center of Chinese People's Liberation Army General Hospital, Beijing, China; ${ }^{3}$ Department of Radiology, First Medical \\ Center of Chinese People's Liberation Army General Hospital, Beijing, China \\ Contributions: (I) Conception and design: G Liu, ZL Wang; (II) Administrative support: G Liu, ZL Wang; (III) Provision of study materials or \\ patients: MK Zhang, QJ Shang; (IV) Collection and assembly of data: MK Zhang, SY Li; (V) Data analysis and interpretation: MK Zhang, SY Li, B \\ Wang; (VI) Manuscript writing: All authors; (VII) Final approval of manuscript: All authors. \\ "These authors contributed equally to this work as co-first authors. \\ Correspondence to: Zhi Li Wang; Gang Liu. First Medical Center of Chinese People's Liberation Army General Hospital, 28 Fuxing Road, Beijing \\ 100853, China. Email: wzllg@sina.com; 13611245784@126.com.
}

Background: This study aimed to explore whether transforming growth factor $\beta 1$ (TGF- $\beta 1$ ) is correlated with the stiffness of breast lesions and if it can predict axillary lymph node (ALN) metastasis.

Methods: A retrospective analysis was performed in our hospital. A total of 135 breast lesions in 130 patients who were to undergo vacuum-assisted excisional biopsy (VAEB) or surgery were enrolled between April 2018 and October 2018. Ultrasound (US) and shear wave elastography (SWE) examinations were performed for every lesion before VAEB or surgery. Pathology results obtained by VAEB or surgery were regarded as gold criteria. The elastic parameters and TGF- $\beta 1$ expression level of malignant breast lesions were compared with those of benign lesions; the relationship between TGF- $\beta 1$ expression level in breast lesions and the elastic parameters was analyzed; the TGF- $\beta 1$ expression level in breast lesions with or without ALN metastasis were compared; and the efficacy of TGF- $\beta 1$ expression level in predicting ALN metastasis was analyzed.

Results: The malignant breast lesions were different from benign lesions in the maximum and mean elasticity (Emax, Emean), standard deviation of elasticity (ESD), elastic ratio of the lesions to the peripheral tissue (Eratio), and the occurrence rate of "stiff rim sign" $(\mathrm{P}<0.001)$. The expression level of TGF- $\beta 1$ in benign breast lesions was significantly lower than that in malignant lesions $(\mathrm{P}<0.001)$, and the TGF- $\beta 1$ expression level was positively correlated with Emax, Emean, ESD, and Eratio ( $r=0.869,0.840,0.834$, and 0.734 , respectively). The expression level of TGF- $\beta 1$ in breast lesions with or without "stiff rim sign" was significantly different $(\mathrm{P}<0.001)$, and the TGF- $\beta 1$ expression level in malignant breast lesions with ALN metastasis was significantly higher than that in malignant lesions without ALN metastasis $(\mathrm{P}=0.0009)$. When TGF- $\beta 1$ expression level $>0.3138$ was taken as the cut-off value, its efficacy in predicting ALN metastasis was 0.853 , with a sensitivity of $86.67 \%$, and a specificity $83.33 \%$.

Conclusions: The expression level of TGF- $\beta 1$ was positively correlated with the elastic parameters of breast lesions, and it could be useful for predicting ALN metastasis, especially for negative ALN diagnosis clinically.

Keywords: Transforming growth factor $\beta 1$ (TGF- $\beta 1$ ); breast lesions; stiffness; axillary lymph node metastasis

Submitted Mar 12, 2021. Accepted for publication May 21, 2021.

doi: 10.21037/atm-21-1705

View this article at: http://dx.doi.org/10.21037/atm-21-1705 


\section{Introduction}

Breast carcinoma has become the most common malignant tumor among women in China, and it is a serious danger to women's health. Breast cancer-specific mortality has continually decreased over the past 10 years. It is possible to cure early breast cancer (1), so the importance of early diagnosis has been emphasized by the World Health Organization (WHO). The approaches to breast carcinoma management include surgery and other systemic options, such as radiation treatment, chemotherapy, endocrine therapy, and targeted agents, which depend on histological grade, tumor size, hormone receptor status, axillary lymphatic metastasis and so on (2). The axillary lymph node (ALN) status is one of the most important prognostic factors in patients with breast cancer. It was reported that the strongest predictor of ALN metastasis was lymphovascular invasion, followed by histology grade, tumor size, and epidermal growth factor receptor 2 status (3). Sentinel lymph node (SLN) biopsy is now the standard procedure in patients with clinically node-negative breast cancer. For patients with needle biopsy-proven axillary metastatic nodal disease, the most widely accepted clinical staging method is sentinel lymph node resection (4).

It has been demonstrated by many studies that shear wave elastography (SWE) can improve the differential diagnostic performance of ultrasound (US) in breast lesions $(5,6)$. The SWE parameters to evaluate benign and malignant breast lesions include maximum elasticity (Emax), mean elasticity (Emean), minimum elasticity (Emin), elasticity standard deviation (ESD), the elasticity ratio of the lesions to the peripheral tissue (Eratio), and "stiff rim sign". Previous studies have shown that collagen fibers and elastic fibers, as the main components of extracellular matrix (ECM), were positively correlated with the elastic parameters of breast lesions (7). Andrew Evans et al. (8) also demonstrated that mean stiffness at SWE is an independent predictor of ALN metastasis. And it was reported that tumor stiffness on elastography is independently associated with ALN metastasis in patients with T1 breast carcinoma (9).

Transforming growth factor- $\beta 1$ (TGF- $\beta 1$ ), as a master regulator, plays a crucial role in the deposition and structural rearrangement of the ECM in breast carcinoma, including collagen and elastic fibers, and the process of epithelial-to-mesenchymal transition (EMT) $(10,11)$. The process of EMT, leading the loss of epithelial properties and the acquisition of migratory mesenchymal, is a vital step in cancer metastasis (12).

However, little is known about the functional role of TGF- $\beta 1$ in the elasticity differences and ALN metastasis of breast lesions. Therefore, the current study aimed to evaluate the effect of TGF- $\beta 1$ expression on the differential diagnosis of benign and malignant breast lesions, and to analyze the relationship between TGF- $\beta 1$ and SWE parameters and ALN metastasis. We present the following article in accordance with the STARD reporting checklist (available at http://dx.doi.org/10.21037/atm-21-1705).

\section{Methods}

\section{Participants}

Between April 2018 and October 2018, 135 lesions in 130 patients were recruited to this retrospective study, and were examined with conventional US and SWE. The participants were $18-73$ years old, with an average age of $38.8 \pm 10.7$ years old. The largest diameter of the lesions was $0.4-5.5 \mathrm{~cm}$ (mean size \pm standard deviation, $1.6 \pm 0.8 \mathrm{~cm}$ ). We performed US-guided vacuum-assisted excisional biopsy (VAEB) or surgical resection followed by US and SWE examination. The pathology results obtained by VAEB or surgery were regarded as gold criteria. The trial was conducted in accordance with the Declaration of Helsinki (as revised in 2013). The study was approved by the Ethics Committee of the Chinese PLA General Hospital (No. S2020-33601 ), and informed consent was taken from all individual participants.

Patients were included if they met the following criteria: (I) clear pathological diagnosis; (II) had not received neoadjuvant chemotherapy or radiotherapy; (III) complete clinical, pathological, and follow-up information; (IV) had signed the written informed consent. The exclusion criteria were as follows: (I) had received neoadjuvant chemotherapy or radiotherapy; (II) lack of clinical, pathological, and follow-up information.

\section{US and SWE examination}

Using AixPlorer US system (SuperSonic Imagine, Aixen-Provence, France) with a L14-5 linear array probe operating at 4-15 MHz, SWE was performed after conventional US. The same sonographer with more than 10 years of clinical experience, performed all US and SWE examinations. The basic information of the lesion and the presence or absence of ALN metastasis were obtained by 
conventional US, which was then converted to the SWE mode. The SWE imaging was performed in 2 perpendicular planes for each lesion with minimal pressure, lasting for approximately 10 seconds until stable color maps were generated. Elastography boxes were adjusted to encompass the maximum areas of stiffness, including at least $5 \mathrm{~mm}$ of normal breast tissue adjacent to the lesions, because the maximum areas in malignant lesions were always found in the peritumoral region of the lesion, coded in orange or red, which was the origin of the stiff ring sign (13). Emax, Emean, Emin, ESD, "stiff rim sign", and Eratio in 2 perpendicular planes were recorded and the mean was calculated. The Eratio was obtained by placing the ROI in normal breast tissue at the same depth as the lesion.

\section{The acquisition of pathological results}

Participants with Breast Imaging Reporting and Data System (BI-RADS) category 3 or 4 a lesions diagnosed by conventional US and SWE underwent US-guided VAEB. Participants with BI-RADS category $4 \mathrm{~b}, 4 \mathrm{c}$, and 5 lesions underwent surgical resection. If ALN was clinically positive, ALN dissection was necessary. If ALN was clinically negative, SLN biopsy was necessary. After resection, careful histologic assessment of resection was essential.

\section{TGF-ק1 detection}

The lesions were fixed with formalin, paraffin-embedded, and cut into $4 \mu \mathrm{m}$ slices. Then, TGF- $\beta 1$ was detected by immunohistochemistry (IHC). The staining results of IHC were analyzed using Image-Pro Plus 6.0 software (Media Cybernetics, Rockville, MD, USA). A total of 5 areas of interest were taken from each slice under $400 \times$ field of view and photographed. After measuring the integrated optical density (IOD) and area, average optical density (IOD/area) was used to evaluate the expression level of TGF- $\beta 1$.

\section{Statistical analysis}

All data were analyzed using SPSS 23.0, standard version (SPSS Inc, Chicago, IL, USA). The measurement data were expressed as mean \pm SD and count data as percentage (\%). Independent sample $t$-test was used to compare the TGF- $\beta 1$ expression level, Emax, Emean, Emin, ESD, and Eratio of benign and malignant breast lesions. The chi-square $\left(\chi^{2}\right)$ test was used to compare the incidence of "stiff rim sign" in benign and malignant lesions. Receiver operating characteristic (ROC) curves were constructed for TGF- $\beta 1$ expression levels in differentiating benign from malignant breast lesions and predicting the negative or positive ALN metastasis. The sensitivity, specificity, and optimal cutoff values were calculated, respectively. Spearman correlation analysis was used to assess the correlation between TGF- $\beta 1$ expression level and elastic parameters in breast lesions, and the correlation coefficient was calculated. A value of $\mathrm{P}<0.05$ was considered statistically significant.

\section{Results}

\section{Pathological results}

Of the 135 breast lesions, 84 (62.2\%) were benign, including 32 fibroadenomas, 40 adenosis, 3 intraductal papillomas, 8 inflammatory lesions, and 1 benign phyllode tumor. There were $51(37.8 \%)$ malignant tumors, including 46 invasive cancers, 3 intraductal cancers, and 2 mucinous cancers. Of the 51 malignant tumors, 15 (29.4\%) were positive axillary lymphatic metastases, and $36(70.6 \%)$ were clinically negative.

\section{The elastic parameters of benign and malignant breast lesions}

The Emax, Emean, ESD, Eratio, and the occurrence rate of "stiff rim sign" of malignant breast lesions were significantly higher than those of benign lesions $(\mathrm{P}<0.001)$, while the Emin of benign breast lesions and malignant lesions was not significantly different $(\mathrm{P}=0.221)$. The comparation of the elastic parameters between benign breast lesions and malignant lesions is shown in Table 1 and Figure 1.

\section{The expression level of TGF- $\beta 1$ in benign and malignant breast lesions}

The mean expression level of TGF- $\beta 1$ in 135 breast lesions was $0.1702 \pm 0.1124$, and the expression level of TGF- $\beta 1$ in malignant breast lesions was significantly higher than that in benign breast lesions $(0.2826 \pm 0.0643$ vs. $0.1020 \pm 0.0737$, $\mathrm{P}<0.001$ ) (Table 1, Figure 2). The expression level of TGF- $\beta 1$ was used for the differential diagnosis of benign and malignant breast lesions with an efficacy of 0.943 (0.903-0.982), the sensitivity and specificity of TGF- $\beta 1$ expression level in differential diagnosis of benign and malignant lesions were $94.1 \%$ and $90.5 \%$, respectively, when average optical density $>0.2178$ was taken as the cutoff value (Figure 3). 
Table 1 The elastic parameters and the TGF- $\beta 1$ expression level of benign and malignant breast lesions

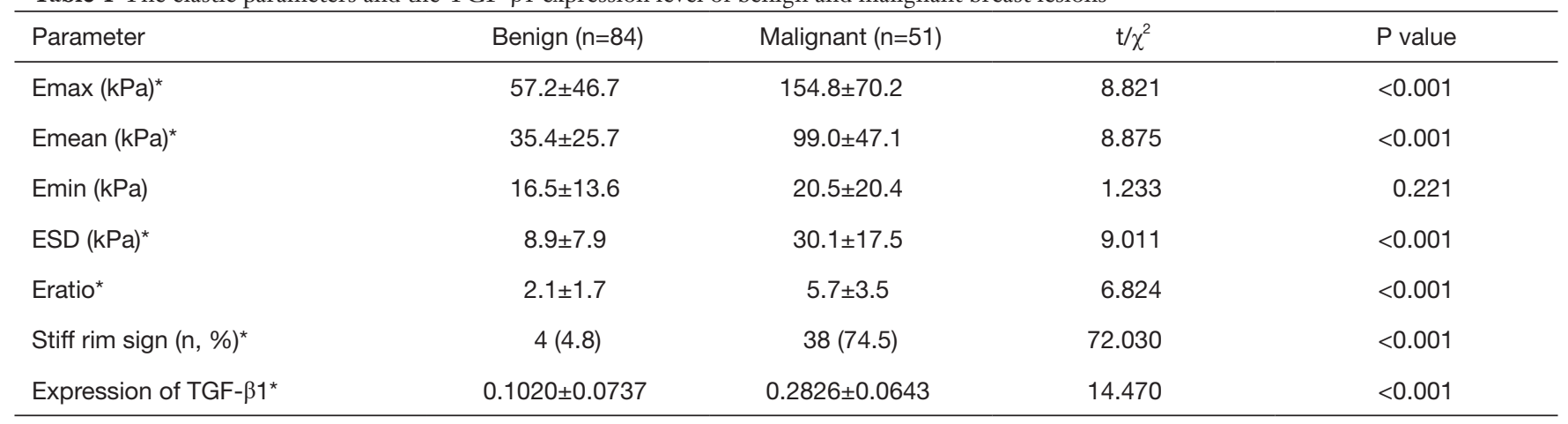

*, a value of $\mathrm{P}<0.05$ is considered statistically significant. TGF- $\beta 1$, transforming growth factor $\beta 1$; Emax, maximum elasticity; Emean, mean elasticity; ESD, elasticity standard deviation; Eratio, the elasticity ratio of the lesions to the peripheral tissue; Emin, minimum elasticity.
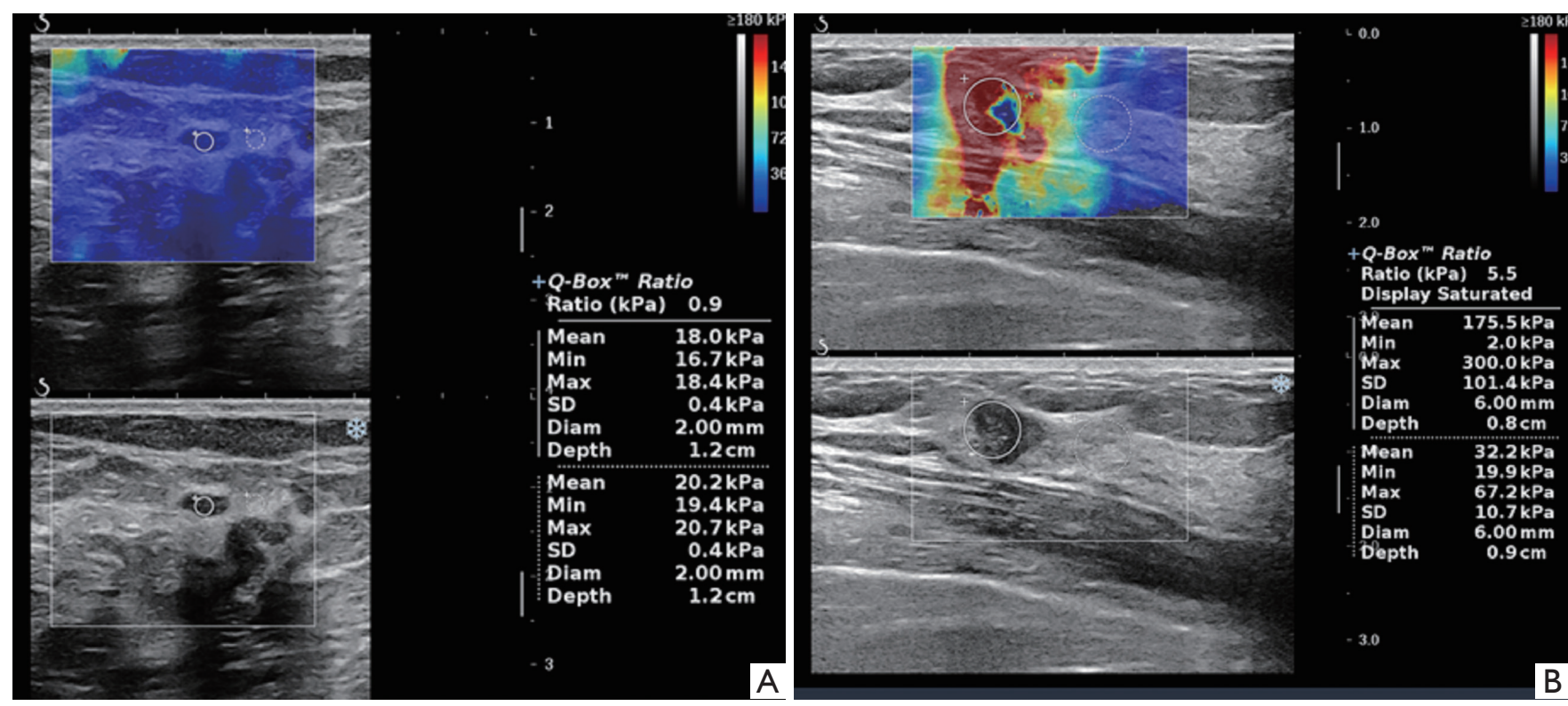

Figure 1 Elastic parameters of breast lesions. (A) SWE image of a 49-year-old female patient with breast adenopathy. The Emax, Emean, ESD, and Eratio were $18.4 \mathrm{kPa}, 18.0 \mathrm{kPa}, 0.4 \mathrm{kPa}$, and 0.9, respectively; (B) SWE image of a 43 -year-old female patient with breast invasive carcinoma. The Emax, Emean, ESD, and Eratio were $300.0 \mathrm{kPa}, 175.5 \mathrm{kPa}, 101.4 \mathrm{kPa}$, and 5.5, respectively, the "stiff rim sign" was visible (the white arrow). SWE, shear wave elastography; Emax, maximum elasticity; Emean, mean elasticity; ESD, elasticity standard deviation; Eratio, the elasticity ratio of the lesions to the peripheral tissue.

\section{The expression level of TGF- $\beta 1$ in elastic parameter}

The expression level of TGF- $\beta 1$ was strongly positively correlated with the Emax, Emean, ESD, and Eratio of breast lesions ( $\mathrm{r}=0.869,0.840,0.834$, and 0.734 , respectively. $\mathrm{P}<0.001$ ) (Figure $4 A, B, C, D)$. The expression level of TGF- $\beta 1$ was weakly positively correlated with the Emin $(\mathrm{r}=0.265, \mathrm{P}<0.01)$ (Figure 4E). In addition, the expression level of TGF- $\beta 1$ in breast lesions with "stiff rim sign"
$(0.2915 \pm 0.0571)$ was significantly higher than that in breast lesions without "stiff rim sign" $(0.1154 \pm 0.0848, \mathrm{P}<0.001)$ (Figure 5).

\section{The expression level of TGF-ק1 in axillary lymphatic metastasis}

The expression levels of TGF- $\beta 1$ in breast lesions with 

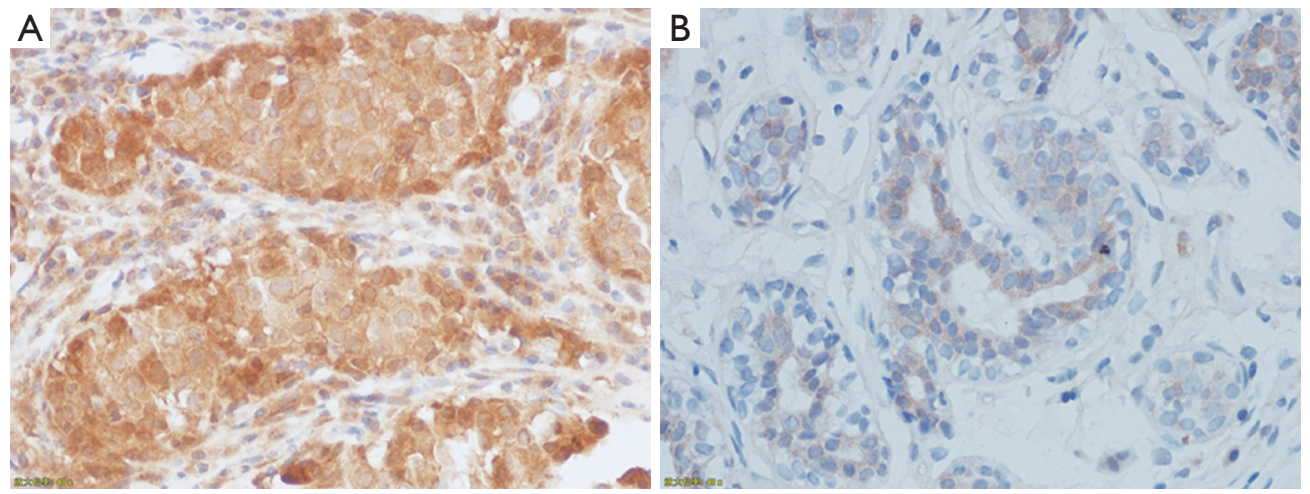

Figure 2 The expression level of TGF- $\beta 1$ in breast lesions. (A) IHC $(\times 400)$ image of a 28 -year-old female patient with breast fibroadenoma. The average optical density was 0.0546 ; (B) IHC $(\times 400)$ image of a 63 -year-old female patient with breast invasive carcinoma. The average optical density was 0.3423 . IHC, immunohistochemistry.

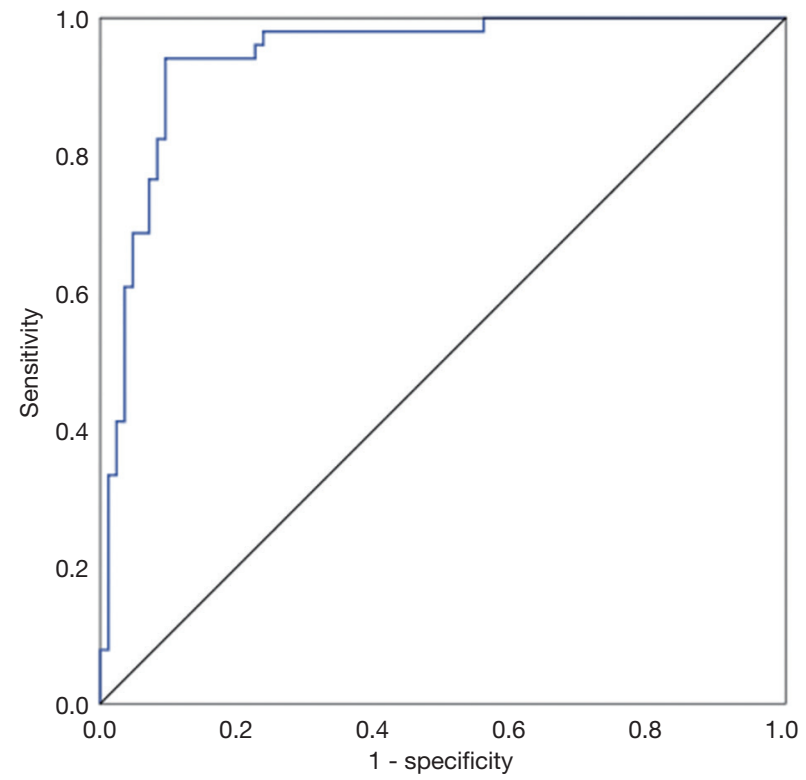

Figure 3 The ROC curve of TGF- $\beta 1$ expression level in differential diagnosis of benign and malignant breast lesions. ROC, receiver operating characteristic; TGF- $\beta 1$, transforming growth factor $\beta 1$.

positive ALN metastasis $(0.3317 \pm 0.0364)$ was significantly higher than in those with negative axillary lymphatic metastasis $(0.2606 \pm 0.0703, \mathrm{P}<0.001)$ (Figure 6). The efficacy was $0.853(0.703-0.946)$ when TGF- $\beta 1$ was used for predicting ALN metastasis of malignant breast lesions (Figure 7), the sensitivity and specificity for TGF- $\beta 1$ expression level to predict ALN metastasis was $86.67 \%$ and $83.33 \%$, respectively, when the cutoff value was average optical density $>0.3138$ (Figure 7).

\section{Discussion}

The SWE method can quantitatively evaluate breast lesions and provide more objective information; thus, for breast lesions, elastic parameters play an important role in the differential diagnosis of benign and malignant breast lesions, which has been confirmed by many studies $(6,14,15)$. Our study showed that compared with benign breast lesions, malignant lesions had higher Emax, Emean, ESD, Eratio, and occurrence rate of "stiff rim sign", which was consistent with the results of several previous studies $(6,16)$. The Emean, Emax, and Eratio were significantly associated with histological grade, and peripheral lymphatic or vascular invasion (17-20). The ESD reflected homogeneity inside the lesion, while the components inside malignant lesions were often more complex than benign lesions. Through proteolytic cleavage, tumor cells at the tumor boundary contracted and rearranged the collagen fibers, and then invaded and metastasized along the rearranged collagen (21). The infiltration of cancer cells into the surrounding mesenchymal tissues, and the desmoplastic reaction at the tumor edge due to the invasion of cancer cells could all lead to the occurrence of "stiff rim sign" (13). Therefore, it is not difficult to understand the results of this study.

In our study, it was shown that there was no significant difference in Emin between benign and malignant lesions. This particular result was not consistent with those of previous studies. Hari et al. showed that the Emin of malignant lesions was significantly higher than that of 

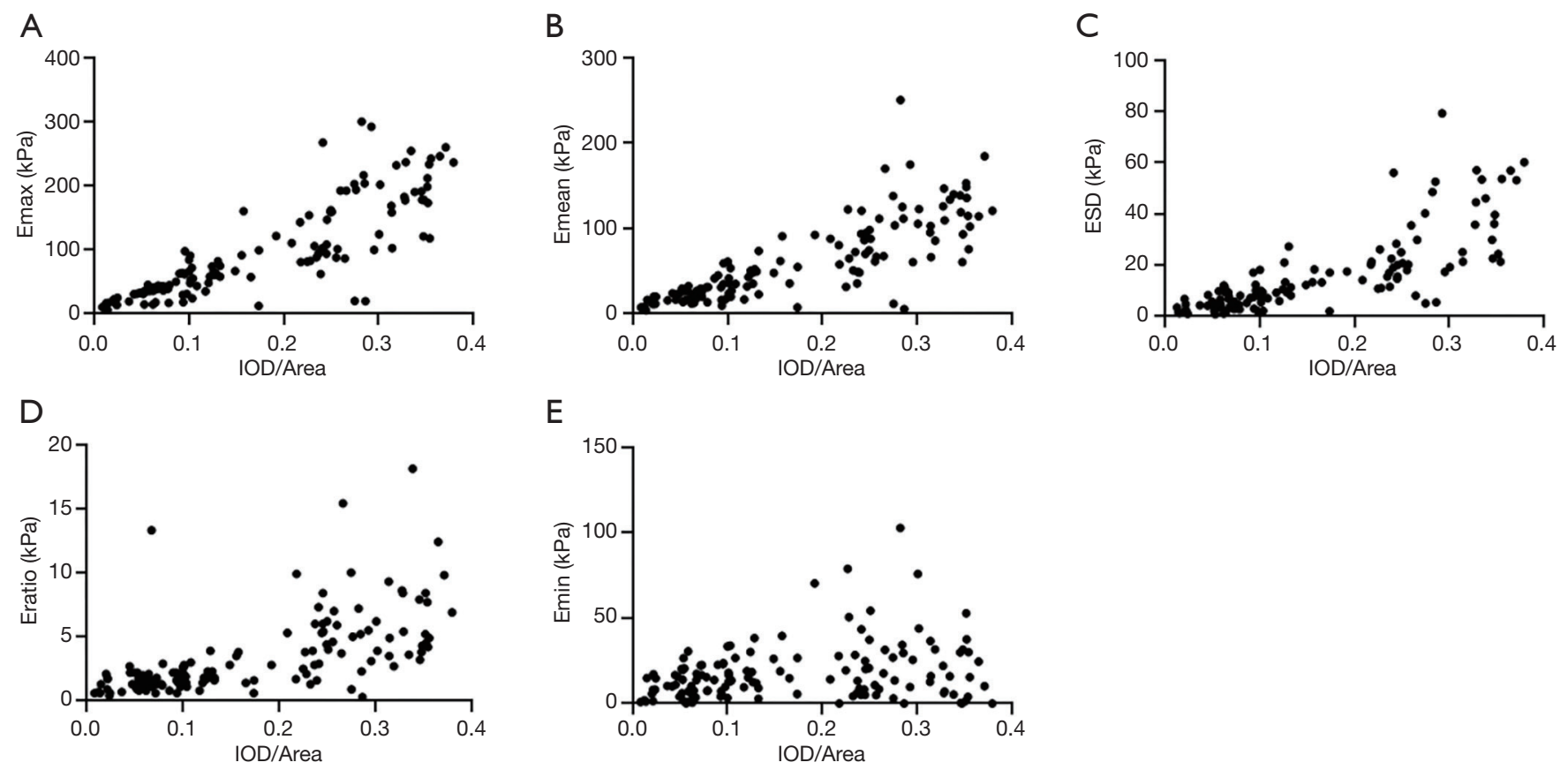

Figure 4 The expression level of TGF- $\beta 1$ was positively correlated with Emax, Emean, ESD, Eratio, and Emin (r=0.869, 0.840, 0.834, 0.734 , and 0.265 , respectively. $\mathrm{P}<0.01$ ). TGF- $\beta 1$, transforming growth factor $\beta 1$; Emax, maximum elasticity; Emean, mean elasticity; ESD, elasticity standard deviation; Eratio, the elasticity ratio of the lesions to the peripheral tissue; Emin, minimum elasticity.

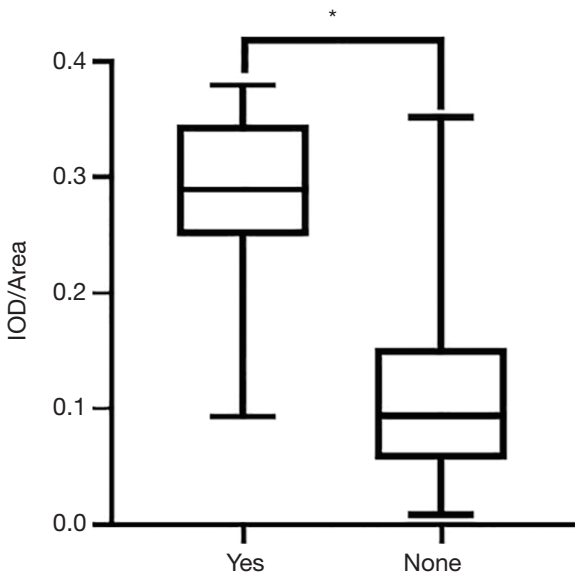

Figure 5 The expression level of TGF- $\beta 1$ in breast lesions with or without "stiff rim sign" (*, difference was statistically significant). TGF- $\beta 1$, transforming growth factor $\beta 1$.

benign lesions (22), while Zhou et al. showed that Emin of malignant lesions was significantly lower than that of benign lesions (13). The phenomenon related to the obtainment of histological sampling and heterogeneity of breast cancer cells, where part of the ECM had not been invaded by

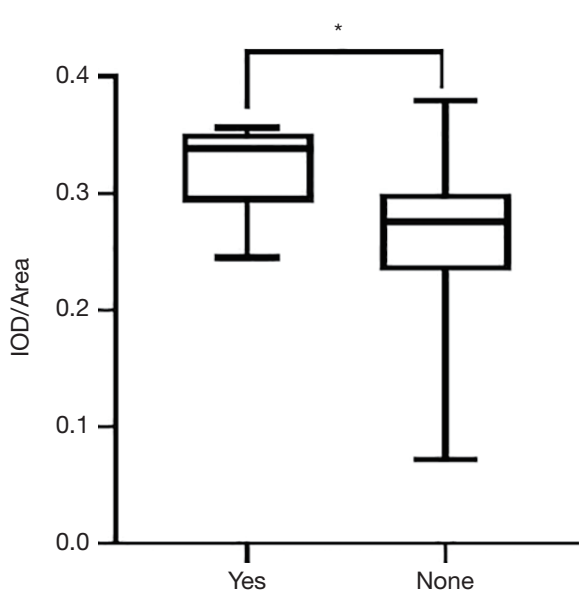

Figure 6 The expression levels of TGF- $\beta 1$ in breast lesions with positive or negative ALN metastasis (* difference was statistically significant). TGF- $\beta 1$, transforming growth factor $\beta 1$; ALN, axillary lymph node.

tumor cells.

As a cytokine, TGF- $\beta 1$ plays an important role in the proliferation and metastasis of breast cancer cells $(23,24)$. On the one hand, TGF- $\beta 1$ could promote the immune 


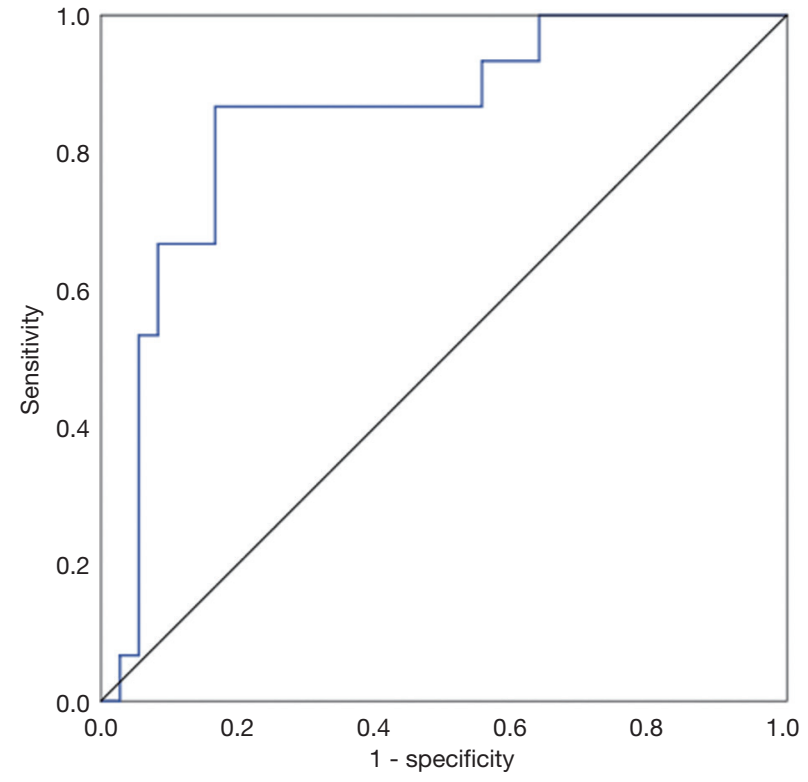

Figure 7 The ROC curve of TGF- $\beta 1$ for predicting ALN metastasis of malignant breast lesions. ROC, receiver operating characteristic; TGF- $\beta 1$, transforming growth factor $\beta 1$; ALN, axillary lymph node.

response of cancer cells to escape host immune response by transforming $\mathrm{T}$ cells into regulatory $\mathrm{T}$ cells, and on the other hand, it could induce the EMT of cancer cells, thus promoting metastasis $(25,26)$. The proliferation of cancer cells increases the secretion of TGF- $\beta 1$, which further promotes metastasis (27). Accordingly, the result of this study showed that TGF- $\beta 1$ expression level in malignant breast lesions was significantly higher than that in benign breast lesions, which was as expected.

Our study found that the expression level of TGF- $\beta 1$ played an important role in differential diagnosis of benign and malignant breast lesions, and the optimal cutoff value was 0.3138 with a sensitivity of $94.1 \%$ and a specificity of $90.5 \%$, which suggested that TGF- $\beta 1$ might be an indicator for the differential diagnosis of benign and malignant breast lesions. Small molecule TGF- $\beta 1$ inhibitors have been shown to be feasible in the prevention and treatment of breast cancer metastasis. Currently, TGF- $\beta 1$ short hairpin RNA (shRNA), TGF- $\beta 1$ blocking antibodies, and TGF- $\beta 1$ receptor inhibitors have been shown to be effective in preventing tumor development and metastasis (28-30). Therefore, TGF- $\beta 1$ might also be used as a biological target for the treatment and prevention of breast cancer, bringing hope for breast cancer patients in China.
The present study showed that the expression level of TGF- $\beta 1$ was strongly positively correlated with the Emax, Emean, ESD, and Eratio of breast lesions and was weakly positively correlated with Emin. The results were consistent with previous studies that found TGF- $\beta 1$ caused an increase in the level of collagen and fibronectin, the main components of the ECM, and caused their rearrangement, resulting in structural changes that increased the stiffness of ECM $(31,32)$ and that of the lesion. The results suggested that TGF- $\beta 1$ might participate in regulating the stiffness of breast lesions.

Besides, in this study, the expression level of TGF- $\beta 1$ in breast lesions with "stiff rim sign" was shown to be higher than that in breast lesions without "stiff rim sign". The occurrence of "stiff rim sign" was mainly due to the invasion of cancer cells into the surrounding stromal tissue and the desmoplastic response caused by the invasion of cancer cells (13); TGF- $\beta 1$ was associated with the proliferation, invasion, and metastasis of breast lesions, so the result of this study was easy to fathom.

ALN metastasis is a complex process, during which breast cancer cells migrate away from the primary site through the afferent lymphatic vessel, and lodge and grow to form metastases. In this study, we demonstrated that the expression levels of TGF- $\beta 1$ in breast lesions with positive axillary lymphatic metastasis was significantly higher than that in negative ones. This phenomenon was also seen in the study by Zhang et al., which demonstrated that TGF- $\beta 1$ promotes pulmonary metastasis of breast cancer (24). Although fundamental questions of when, how, and why breast cancer cells disseminate through the lymphatic system remain largely unanswered. This can be partially explained by TGF- $\beta 1$ inducing EMT, which allows cancer breast cells to dedifferentiate and acquire enhanced migratory and invasive properties, thus leading to the dissemination of cancer cells (33).

In addition, 5 cases were pathologically confirmed as ALN metastasis, with negative ultrasound diagnosis and positive TGF- $\beta 1$ expression level prediction; thus, the value of the expression level of TGF- $\beta 1$ in breast lesions in predicting ALN metastasis was demonstrated in this study, especially for those who have clinically negative ALN metastasis at the time of diagnosis. If the TGF- $\beta 1$ expression level $>0.3138$, it could predict ALN metastasis with high sensitivity (86.67\%) and specificity (83.33\%). Further research is required regarding whether the resection of ALN is necessary if the IOD/area $>0.3138$ 
with negative clinical ALN metastasis diagnosis. This might provide a novel surgical treatment idea for clinically diagnosed negative ALN metastatic breast cancer. Real-time elastography and SWE were also reported to be good tools for the diagnosis of ALN metastasis. The sensitivity and specificity were $78 \%$ and $93 \%$ for real-time elastography, $96.0 \%$ and $56.1 \%$ for SWE $(34,35)$. Future research could combined the TGF- $\beta 1$ expression and ALN elastography in order to get a better diagnostic accuracy.

There were some limitations in this study. First, the sample of the study was not large enough to have a precise analysis of the expression level of TGF- $\beta 1$ in predicting ALN metastasis. Future research should include more cases of clinically diagnosed negative ALN to evaluate whether resection of ALN is necessary in the instance of IOD/area $>0.3138$ combined with negative ALN diagnosis clinically. Second, sampling bias in TGF- $\beta 1$ detection was inescapable.

In conclusion, the expression of TGF- $\beta 1$ is higher in malignant breast lesions. The expression level of TGF- $\beta 1$ was positively correlated with the elastic parameters of breast lesions, and it could also predict the presence or absence of ALN metastasis in malignant breast lesions. The role of TGF- $\beta 1$ might be that of regulating the stiffness of breast lesions and predicting ALN metastasis, especially for negative ALN diagnosis clinically.

\section{Acknowledgments}

Funding: This work was supported by the National Natural Science Foundation (81771832, 82071925); and the Military Top project of Youth Training for Medical Science and Technology (19QNP071).

\section{Footnote}

Reporting Checklist: The authors have completed the STARD reporting checklist. Available at http://dx.doi.org/10.21037/ atm-21-1705

Data Sharing Statement: Available at http://dx.doi. org/10.21037/atm-21-1705

Conflicts of Interest: All authors have completed the ICMJE uniform disclosure form (available at http://dx.doi. org/10.21037/atm-21-1705). The authors have no conflicts of interest to declare.
Ethical Statement: The authors are accountable for all aspects of the work in ensuring that questions related to the accuracy or integrity of any part of the work are appropriately investigated and resolved. The trial was conducted in accordance with the Declaration of Helsinki (as revised in 2013). The study was approved by the Ethics Committee of the Chinese PLA General Hospital (No. S2020-336-01), and informed consent was taken from all individual participants.

Open Access Statement: This is an Open Access article distributed in accordance with the Creative Commons Attribution-NonCommercial-NoDerivs 4.0 International License (CC BY-NC-ND 4.0), which permits the noncommercial replication and distribution of the article with the strict proviso that no changes or edits are made and the original work is properly cited (including links to both the formal publication through the relevant DOI and the license). See: https://creativecommons.org/licenses/by-nc-nd/4.0/.

\section{References}

1. Harbeck N, Gnant M. Breast cancer. Lancet 2017;389:1134-50.

2. Mcdonald ES, Clark AS, Tchou J, et al. Clinical Diagnosis and Management of Breast Cancer. J Nucl Med 2016;57 Suppl 1:9S-16S.

3. Tseng HS, Chen LS, Kuo SJ, et al. Tumor characteristics of breast cancer in predicting axillary lymph node metastasis. Med Sci Monit 2014;20:1155-61.

4. Arjmandi F, Mootz A, Farr D, et al. New horizons in imaging and surgical assessment of breast cancer lymph node metastasis. Breast Cancer Res Treat 2021. [Epub ahead of print]. doi: 10.1007/s10549-021-06248-x.

5. Skerl K, Vinnicombe S, Giannotti E, et al. Influence of region of interest size and ultrasound lesion size on the performance of 2D shear wave elastography (SWE) in solid breast masses. Clin Radiol 2015;70:1421-7.

6. Xue Y, Yao S, Li X, et al. Value of shear wave elastography in discriminating malignant and benign breast lesions: A meta-analysis. Medicine (Baltimore) 2017;96:e7412.

7. Liu G, Zhang MK, He Y, et al. Shear wave elasticity of breast lesions: would it be correlated with the extracellular matrix components? Gland Surg 2019;8:399-406.

8. Evans A, Rauchhaus P, Whelehan P, et al. Does shear wave ultrasound independently predict axillary lymph node metastasis in women with invasive breast cancer? Breast 
Cancer Res Treat .2014;143:153-7.

9. Yi A, Moon WK, Cho N, et al. Association of tumour stiffness on sonoelastography with axillary nodal status in T1 breast carcinoma patients. Eur Radiol 2013;23:2979-87.

10. Katsuno Y, Lamouille S, Derynck R. TGF-beta signaling and epithelial-mesenchymal transition in cancer progression. Curr Opin Oncol 2013;25:76-84.

11. Arimura H, Shukunami C, Tokunaga T, et al. TGFbeta 1 Improves Biomechanical Strength by Extracellular Matrix Accumulation Without Increasing the Number of Tenogenic Lineage Cells in a Rat Rotator Cuff Repair Model. Am J Sports Med 2017;45:2394-404.

12. Chen Q, Yang W, Wang X, et al. TGF- $\beta 1$ Induces EMT in Bovine Mammary Epithelial Cells Through the TGFß1/Smad Signaling Pathway. Cell Physiol Biochem 2017;43:82-93.

13. Zhou J, Zhan W, Chang C, et al. Breast lesions: evaluation with shear wave elastography, with special emphasis on the “stiff rim" sign. Radiology 2014;272:63-72.

14. Athanasiou A, Tardivon A, Tanter M, et al. Breast lesions: quantitative elastography with supersonic shear imaging-preliminary results. Radiology 2010;256:297-303.

15. Cosgrove DO, Berg WA, Dore C J, et al. Shear wave elastography for breast masses is highly reproducible. Eur Radiol 2012;22:1023-32.

16. Ng WL, Rahmat K, Fadzli F, et al. Shearwave Elastography Increases Diagnostic Accuracy in Characterization of Breast Lesions. Medicine (Baltimore) 2016;95:e3146.

17. Youk JH, Gweon HM, Son EJ, et al. Shear-wave elastography of invasive breast cancer: correlation between quantitative mean elasticity value and immunohistochemical profile. Breast Cancer Res Treat 2013;138:119-26.

18. Au FW, Ghai S, Lu FI, et al. Quantitative shear wave elastography: correlation with prognostic histologic features and immunohistochemical biomarkers of breast cancer. Acad Radiol 2015;22:269-77.

19. Cho EY, Ko ES, Han BK, et al. Shear-wave elastography in invasive ductal carcinoma: correlation between quantitative maximum elasticity value and detailed pathological findings. Acta Radiol 2016;57:521-8.

20. Choi WJ, Kim HH, Cha JH, et al. Predicting prognostic factors of breast cancer using shear wave elastography. Ultrasound Med Biol 2014;40:269-74.

21. Provenzano PP, Eliceiri KW, Campbell JM, et al. Collagen reorganization at the tumor-stromal interface facilitates local invasion. BMC Med 2006;4:38

22. Hari S, Paul SB, Vidyasagar R, et al. Breast mass characterization using shear wave elastography and ultrasound. Diagn Interv Imaging 2018;99:699-707.

23. Drabsch Y, Ten Dijke P. TGF-beta signaling in breast cancer cell invasion and bone metastasis. J Mammary Gland Biol Neoplasia 2011;16:97-108.

24. Zhang F, Dong $W$, Zeng $W$, et al. Naringenin prevents TGF- $\beta 1$ secretion from breast cancer and suppresses pulmonary metastasis by inhibiting PKC activation. Breast Cancer Res 2016;18:38.

25. Tran TT, Uhl M, Ma JY, et al. Inhibiting TGF-beta signaling restores immune surveillance in the SMA-560 glioma model. Neuro Oncol 2007;9:259-70.

26. Rees JR, Onwuegbusi BA, Save VE, et al. In vivo and in vitro evidence for transforming growth factorbeta1-mediated epithelial to mesenchymal transition in esophageal adenocarcinoma. Cancer Res 2006;66:9583-90.

27. Massagué J, Gomis RR. The logic of TGFbeta signaling. FEBS Lett 2006;580:2811-20.

28. Biswas S, Guix M, Rinehart C, et al. Inhibition of TGFbeta with neutralizing antibodies prevents radiationinduced acceleration of metastatic cancer progression. J Clin Invest 2007;117:1305-13.

29. Mazzocca A, Fransvea E, Lavezzari G, et al. Inhibition of transforming growth factor beta receptor I kinase blocks hepatocellular carcinoma growth through neoangiogenesis regulation. Hepatology 2009;50:1140-51.

30. Oh S, Kim E, Kang D, et al. Transforming growth factor-beta gene silencing using adenovirus expressing TGF-beta 1 or TGF-beta2 shRNA. Cancer Gene Ther 2013;20:94-100.

31. Kim KK, Sheppard D, Chapman HA. TGF- $\beta 1$ signaling and tissue fibrosis. Cold Spring Harb Perspect Biol 2018;10:a022293.

32. Wang Z L, Sun L, Li Y, et al. Relationship between elasticity and collagen fiber content in breast disease: a preliminary report. Ultrasonics 2015;57:44-9.

33. Wang Y, Liu X, Zheng H, et al. Suppression of CUL4A attenuates TGF- $\beta 1$-induced epithelial-to-mesenchymal transition in breast cancer cells. Int J Mol Med 2017;40:1114-24.

34. Xu Y, Bai X, Chen Y, et al. Application of Real-time Elastography Ultrasound in the Diagnosis of Axillary Lymph Node Metastasis in Breast Cancer Patients. Sci Rep 2018;8:10234.

35. Ng WL, Omar N, Ab Mumin N, et al. Diagnostic 
Page 10 of 10

Accuracy of Shear Wave Elastography as an Adjunct Tool in Detecting Axillary Lymph Nodes Metastasis. Acad Radiol 2021. [Epub ahead of print]. doi: 10.1016/
Zhang et al. TGF- $\beta 1$, stiffness and axillary lymph node metastasis

j.acra.2021.03.018.

(English Language Editor: J. Jones)

Cite this article as: Zhang MK, Shang QJ, Li SY, Wang B, Liu G, Wang ZL. TGF- $\beta 1$ : is it related to the stiffness of breast lesions and can it predict axillary lymph node metastasis? Ann Transl Med 2021;9(10):870. doi: 10.21037/atm-21-1705 